content of moisture in the various mixtures and the amounts found to be present at the time of examination.

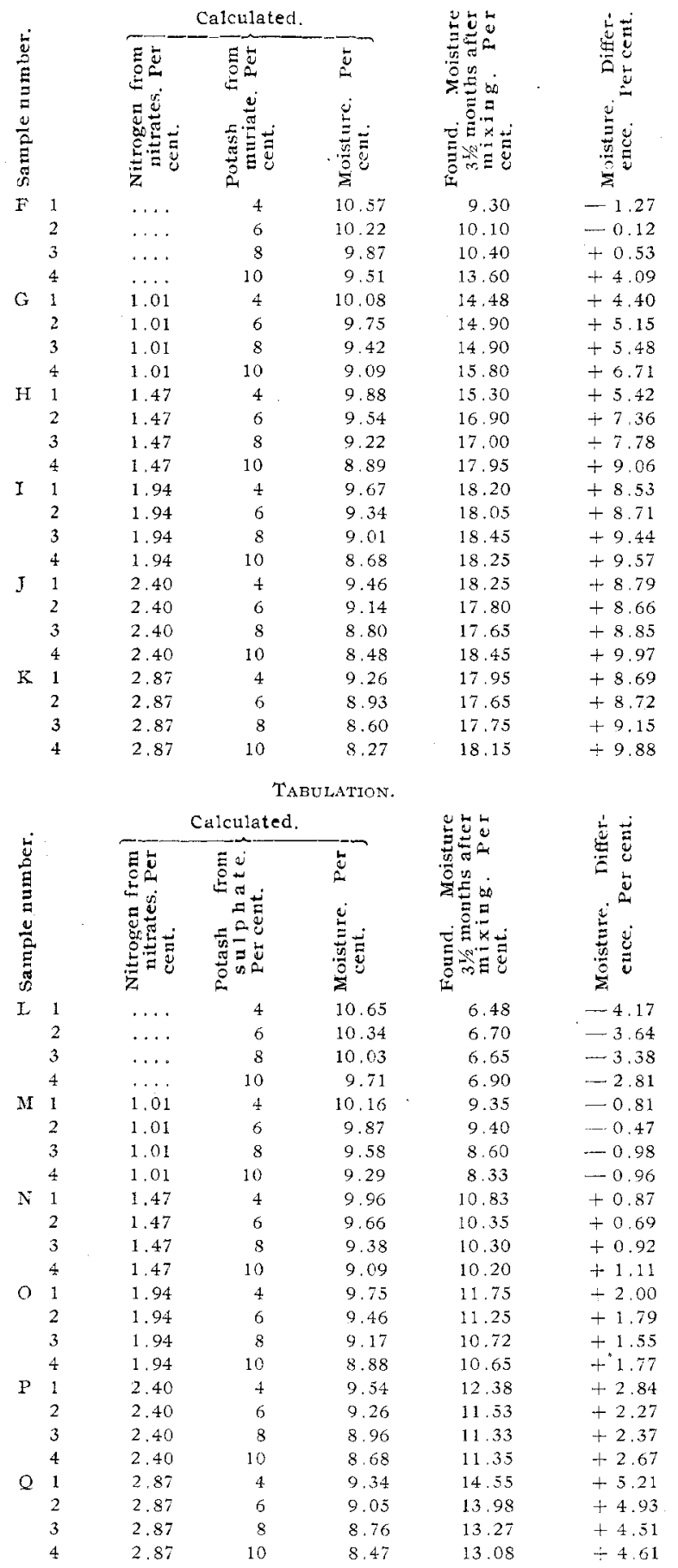

By a survey of the preceding table it will be noticed that the mixtures prepared with sulphate of potash and no nitrate of soda at the time of the examination contained practically the same amount of moisture and the amount found was considerably lower than the calculated content. The corresponding set prepared with muriate of potash contained different percentages of moisture and the figures increased with the per cent. of potash, but in no instance was the water content as low as in the sulphate set.
The results of these two sets of mixtures would indicate that the sulphate of potash did not absorb much, if any, moisture while the muriate did absorb moisture and the quantity of this absorption was greater as the per cent. of potash increased.

The moisture content in each set of the two series increased with the amount of soda added but in every case the set prepared with the muriate contained more than the corresponding set prepared. with the sulphate, and, as found with the set containing no nitrate, the quantity was increased with the per cent. of potash.

All of the samples in the sulphate series, with the exception of set $Q$, were in a good mechanical condition and those in the muriate set containing 1.47 per cent. nitrate nitrogen and from 6 to 10 per cent. potash were no better than those in the other series which contained 2.87 per cent, nitrate nitrogen. Judging from these results, it appears that fertilizer mixtures can be prepared so that they contain as much as 2.50 per cent. nitrate nitrogen and to per cent. potash, stored under severe weather conditions, and will remain in a good mechanical condition, provided the potash is derived from sulphate and not from muriate.

According to the reports of the New Jersey inspections about 6 to 8 per cent. of the brands of commercial fertilizers on the market contain potash in the form of sulphate and, consequently, the poor mechanical condition of many of the commercial brands, after they have been stored for a little time, and particularly those containing a high percentage of potash derived from muriate, can be attributed in part to the muriate of potash that has been used in preparing the mixtures.

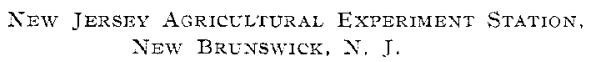

\section{TANKS FOR SOIL INVESTIGATION AT THE FLORIDA AGRICULTURAL EXPERIMENT STATION.}

By A. W. BLAIR AND S. Ë. COLlISON.

Received August. 15, 1910.

While much light can still be thrown on soil and fertilizer problems by carefully conducted field experiments, there yet remain some problems that can never be solved until we can control and measure the factors more accurately than we can in field

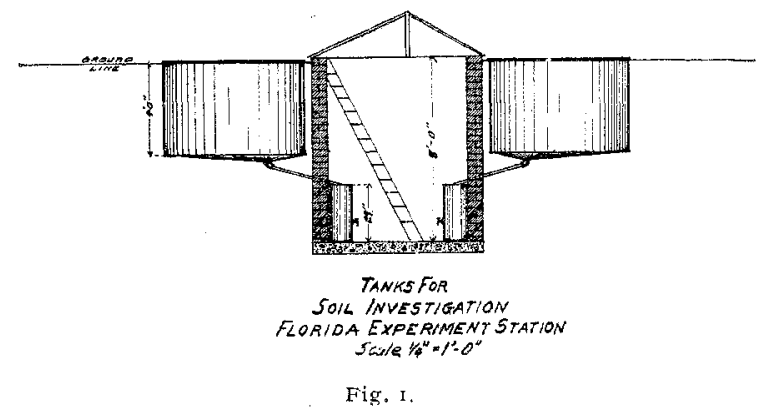

work. To supplement the field work in orange culture that the Florida Experiment Station is conducting, and to make it possible to estimate accurately the loss of soluble fertilizing materials in the drainage 
waters under different systems of fertilizing, and also to investigate the effects of the long-continued use of commercial fertilizers on the soil and on the orange tree, a series of soil tanks has been set up. Each of these tanks has an inside diameter of 5 feet $3^{\mathrm{x}} / 4$ inches, with a maximum depth of $4 \% / 2$ feet, and a surface area of one two-thousandth of an acre. The tanks are constructed of heavy galvanized iron (No. iz gauge), soldered and riveted, and before being placed in the ground they were thoroughly painted inside and out. As may be seen from the accompanying diagrams the bottom of a tank slopes to a point near one side, where there is a strainer opening into a two-inch tin-lined drainage pipe, the length of which is a little more than 4 feet. Four such tanks open into a central collecting pit (one drainage pipe entering at each corner as shown in Fig. 2) where are placed the four receptacles for collecting the drainage waters. Connected with each of these receiving tanks is an overflow tank which is ready for use in case of an emergency (long-continued heavy rains). The collecting pit, which is about $8 \mathrm{ft}$. deep and 6 feet square inside, is built of brick, with a concrete bottom, and is covered.

The soil tanks were sunk in the ground to within a few inches of the top, and filled with soil to within three inches of the edge.

Over the sloping part of the bottom was placed a layer of smooth quartz pebbles, the coarsest material being placed around the drainage opening and the finest on the top. Above this pebble layer was placed
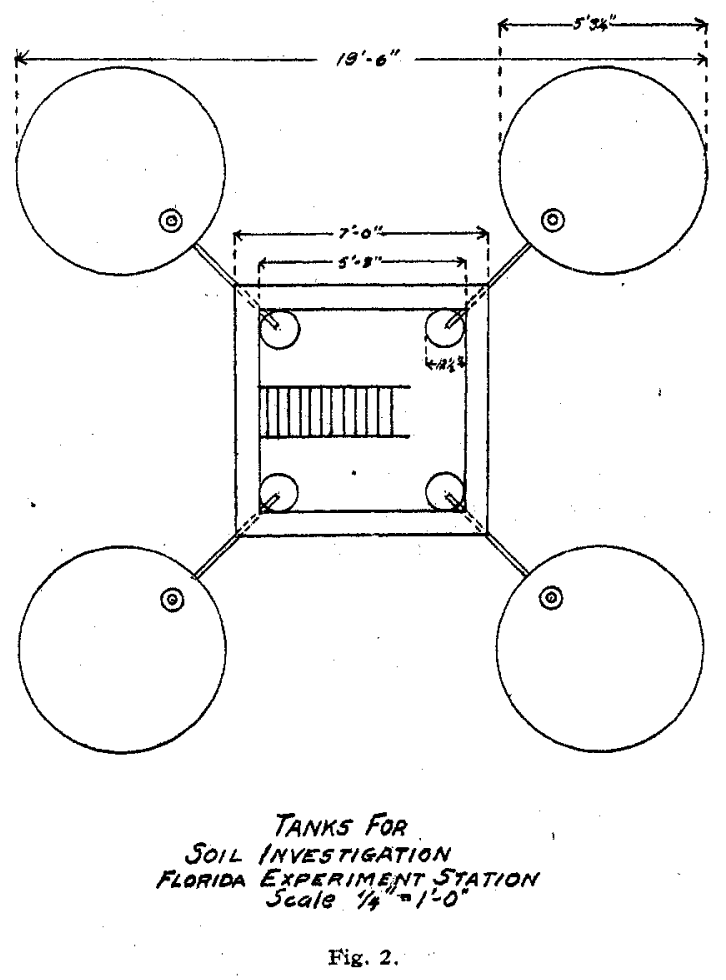

Fig. 2 ,

45 inches of soil, which was put in the tanks in the. following manner. When the soil was dug from the site which each tank was to occupy, the top 9 inches were taken off first, followed by three one-foot sections. All four lots of soil were kept separate. In filling the tanks, the last foot taken from the ground was placed on the gravel in the bottom of the tank, then the next foot, and so on to the top 9 inches. The soil was well tamped a, it was put in, each tank

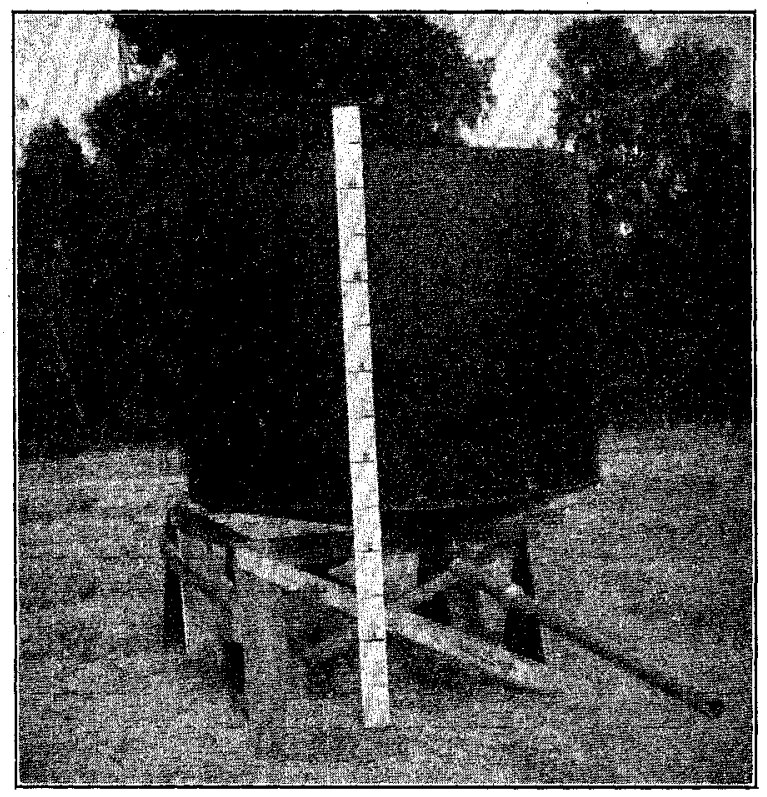

Fig. 3. One of the tanks.

having the same weight of dry soil, 8,625 pounds. The soil is a rather coarse sand, described by the Bureau of Soils as Norfolk sand.

One orange tree has been planted in each tank, and the four trees will be fertilized differently. The tanks are so placed that the trees are about I4 feet apart. Four control trees have been planted a short distance away from the tanks. The tanks are open at the top, and will as far as possible (that is, with due regard to protection from frost) be exposed to natural conditions. Should it become necessary to water artificially, this will be done and a record kept of the amount of water so used. Temperature and rainfall records will also be registered. On the approach of cold waves, the trees will be protected with tents and heaters. It is believed that the tanks will last for a period of $I_{5}$ years or more, a period long enough for much valuable information to be accumulated. The first samples of the drainage waters have been collected and are being analyzed. Additional series of tanks will be added as means are available.

Gainesville, Hia. Aug. 9, 1910.

\section{ADDRESSES.}

\section{PORTLAND CEMENT AS A BY-PRODUCT. ${ }^{1}$}

By J. H. KEMPSTER.

In a paper read before the Section about a year ago by Mr. Touzalin, of the Illinois Steel $\mathrm{Co}_{\text {, }}$ it was stated that while iron is the chief product of the blast furnace, immense industries have been built up from the by-products which for many years were allowed

1 An address delivered before the Chicago Section of the American Chemical Society, November 25, 1910. 